\title{
Management of Acute and Recurrent Gout: A Clinical Practice Guideline From the American College of Physicians
}

\author{
Amir Qaseem, MD, PhD, MHA; Russell P. Harris, MD, MPH; and Mary Ann Forciea, MD; for the Clinical Guidelines Committee of \\ the American College of Physicians*
}

Description: The American College of Physicians (ACP) developed this guideline to present the evidence and provide clinical recommendations on the management of gout.

Methods: Using the ACP grading system, the committee based these recommendations on a systematic review of randomized, controlled trials; systematic reviews; and large observational studies published between January 2010 and March 2016. Clinical outcomes evaluated included pain, joint swelling and tenderness, activities of daily living, patient global assessment, recurrence, intermediate outcomes of serum urate levels, and harms.

Target Audience and Patient Population: The target audience for this guideline includes all clinicians, and the target patient population includes adults with acute or recurrent gout.

Recommendation 1: ACP recommends that clinicians choose corticosteroids, nonsteroidal anti-inflammatory drugs (NSAIDs), or colchicine to treat patients with acute gout. (Grade: strong recommendation, high-quality evidence)
Recommendation 2: $A C P$ recommends that clinicians use low-dose colchicine when using colchicine to treat acute gout. (Grade: strong recommendation, moderate-quality evidence)

Recommendation 3: ACP recommends against initiating longterm urate-lowering therapy in most patients after a first gout attack or in patients with infrequent attacks. (Grade: strong recommendation, moderate-quality evidence)

Recommendation 4: $A C P$ recommends that clinicians discuss benefits, harms, costs, and individual preferences with patients before initiating urate-lowering therapy, including concomitant prophylaxis, in patients with recurrent gout attacks. (Grade: strong recommendation, moderate-quality evidence)

Ann Intern Med. 2017; 166:58-68. doi:10.7326/M16-0570

www.annals.org For author affiliations, see end of text.

This article was published at www.annals.org on 1 November 2016.
G out, one of the most common forms of inflammatory arthritis, is caused by accumulation of excess urate crystals (monosodium urate) in joint fluid, cartilage, bones, tendons, bursas, and other sites. Patients experience joint swelling and pain during gout attacks, known as acute gouty arthritis. In some patients, the frequency and duration of acute attacks increase over time and lead to chronic gout, which may be associated with deposits of uric acid crystals known as tophi. Risk factors for gout include overweight or obesity; hypertension; alcohol intake; diuretic use; a diet rich in meat, seafood, and high-fructose food or drinks; and poor kidney function (1-4). About $3.9 \%$ of U.S. adults older than 20 years report being told at some point that they

\author{
See also: \\ Related articles. . . . . . . . . . . . . . . . 27, 37, 52 \\ Editorial comments ............. 71, 73 \\ Summary for Patients. . . . . . . . . . . . . . . . I-16 \\ Web-Only \\ CME quiz
}

had gout (5). This percentage increased by about $1 \%$ in the 10 years before 2007, probably because of a parallel increase in conditions associated with hyperuricemia. An estimated $\$ 1$ billion is spent annually on ambulatory care for gout, largely on treatments and prescription medications (6).

Management of gout includes both pharmacologic and nonpharmacologic approaches. Pharmacologic therapies focus on urate-lowering strategies and antiinflammatory drugs (Table 1). Nonpharmacologic management focuses on dietary and lifestyle changes, including weight loss and exercise.

\section{Guideline Focus and Target Population}

The purpose of this American College of Physicians (ACP) guideline is to provide guidance on the management of acute and recurrent gout in adults. These recommendations are based on a background evidence paper (7) and a systematic evidence review sponsored by the Agency for Healthcare Research and Quality (AHRQ) (8). For guidance on the diagnosis of gout, please refer to the accompanying ACP guideline (9).

\footnotetext{
* This paper, written by Amir Qaseem, MD, PhD, MHA; Russell P. Harris, MD, MPH; and Mary Ann Forciea, MD, was developed for the Clinical Guidelines Committee of the American College of Physicians. Individuals who served on the Clinical Guidelines Committee from initiation of the project until its approval were Mary Ann Forciea, MD+ (Chair); Thomas D. Denberg, MD, PhD† (Immediate Past Chair); Michael J. Barry, MD†; Cynthia Boyd, MD, MPH†; R. Dobbin Chow, MD, MBA†; Nick Fitterman, MD†; Russell P. Harris, MD, MPH†; Linda L. Humphrey, MD, MPH†; Devan Kansagara, MD, MCR†; Scott Manaker, MD, PhD¥; Robert M. McLean, MD¥; Sandeep Vijan, MD, MS†; and Timothy J. Wilt, MD, MPH†. Approved by the ACP Board of Regents on 7 November 2015.

† Author (participated in discussion and voting).

‡ Nonauthor contributor (participated in discussion but excluded from voting).
} 


\begin{tabular}{|c|c|c|}
\hline \multicolumn{3}{|l|}{ Anti-inflammatory drugs } \\
\hline Ibuprofen & 800 mg 3-4 times daily & $\$ 15$ per $90-d$ supply \\
\hline Naproxen & $750 \mathrm{mg}$, then $250 \mathrm{mg}$ every $8 \mathrm{~h}$ & $\$ 7$ per 60-d supply \\
\hline Diclofenac & 75 mg twice daily & $\$ 21$ per 30-d supply \\
\hline Indomethacin & $50 \mathrm{mg} 3$ times daily & $\$ 10$ per $30-d$ supply \\
\hline Prednisolone & $30-40 \mathrm{mg} / \mathrm{d}$ & $\$ 11$ per 50 -d supply of $15-m g$ dosage \\
\hline Methylprednisolone & $\begin{array}{l}0.5-2.0 \mathrm{mg} / \mathrm{kg} \text { of body weight intravenously or } \\
\text { intramuscularly once }\end{array}$ & $\$ 26$ per $21-d$ supply \\
\hline \multicolumn{3}{|c|}{ 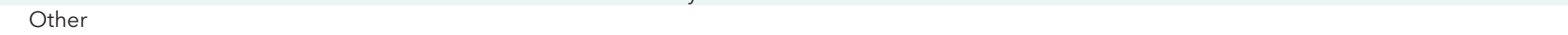 } \\
\hline Animal-derived corticotropin & $40 \mathrm{IU}$ & $\$ 34724$ per injection \\
\hline Colchicine (generic) & $1.2 \mathrm{mg}$ orally, then $0.6 \mathrm{mg} 1 \mathrm{~h}$ later & $\$ 137$ per 30-d supply \\
\hline Colcrys (Takeda Pharmaceuticals) & $1.2 \mathrm{mg}$ orally, then $0.6 \mathrm{mg} 1 \mathrm{~h}$ later & $\$ 192$ per 30-d supply \\
\hline \multicolumn{3}{|l|}{ Xanthine oxidase inhibitors } \\
\hline Allopurinol & $\begin{array}{l}50-100 \mathrm{mg} / \mathrm{d} \text { (lower dose if renal function is impaired) } \\
\text { and increase by } 50-100 \mathrm{mg} / \mathrm{d} \text { every few weeks }\end{array}$ & $\$ 10$ per 30-d supply \\
\hline Zyloprim (Burroughs Wellcome) & $\begin{array}{l}50-100 \mathrm{mg} / \mathrm{d} \text { (lower dose if renal function is impaired) } \\
\text { and increase by } 50-100 \mathrm{mg} / \mathrm{d} \text { every few weeks }\end{array}$ & $\$ 130$ per 30-d supply \\
\hline Febuxostat & $40-80 \mathrm{mg}$ orally once daily & NA \\
\hline Uloric (Takeda Pharmaceuticals) & $40-80 \mathrm{mg}$ orally once daily & $\$ 272$ per 30-d supply \\
\hline \multicolumn{3}{|l|}{ Combination agents } \\
\hline Colchicine-probenecid & Oral, 1 tablet daily for $1 \mathrm{wk}$ & $\$ 42$ per 60 -d supply \\
\hline
\end{tabular}

NA = not available.

* Derived from DynaMed Plus (www.dynamed.com) or the Agency for Healthcare Research and Quality report (8).

† Derived from the Healthcare Bluebook Fair Price (www.healthcarebluebook.com).

‡For celecoxib.

\section{MeTHODS}

\section{Systematic Review of the Evidence}

The evidence review was conducted by the AHRQ's Southern California Evidence-based Practice Center-RAND Corporation. Additional methodological details can be found in the Appendix (available at www .annals.org), as well as in the accompanying article (7) and full report (8). Reviewers searched several databases for studies published from January 2010 to March 2016. Reviewers combined data when possible using meta-analysis and assessed risk of bias and quality of studies according to established methods. The study population included all adults (aged $\geq 18$ years) diagnosed with gout.

The review evaluated nonpharmacologic interventions, including dietary interventions, dietary supplements, and alternative treatments; pharmacologic interventions, including anti-inflammatory drugs, colchicine, urate-lowering therapies, and combination drug bxtherapies; and combinations of drug and dietary or alternative treatments. Evaluated outcomes included intermediate outcome of serum urate levels; health outcomes, such as recurrence, pain, joint swelling and tenderness, activities of daily living, patient global assessment, and development of tophi; and harms.

\section{Grading the Evidence and Developing Recommendations}

This guideline was developed by ACP's Clinical Guidelines Committee (CGC) according to ACP's

www.annals.org guideline development process, details of which can be found in the methods paper (10). The CGC used the evidence tables in the accompanying systematic review (7) and full report (8) when reporting the evidence and graded the recommendations by using the GRADE (Grading of Recommendations Assessment, Development, and Evaluation) approach (Table 2). The authors of the evidence review considered prior physiologic knowledge and indirect and direct evidence when grading the evidence $(11,12)$.

\section{Peer Review}

The AHRQ evidence review was sent to invited peer reviewers and posted on the AHRQ Web site for public comments. The guideline underwent a peer review process through the journal and was posted on line for comments from ACP Regents and ACP Governors, who represent $\mathrm{ACP}$ members at the regional level.

\section{Pharmacologic Treatment of Acute Gout Effectiveness (Benefits and Harms) of Pharmacologic Treatments}

A total of 28 studies assessed pharmacologic gout treatments (13-40).

\section{Colchicine}

Six existing systematic reviews (41-46) reported on the efficacy (health outcomes) of colchicine in treating 
Table 2. The American College of Physicians' Guideline Grading System*

\begin{tabular}{|l|cc|}
\hline \multirow{2}{*}{$\begin{array}{l}\text { Quality of } \\
\text { Evidence }\end{array}$} & \multicolumn{2}{|c|}{ Strength of Recommendation } \\
\cline { 2 - 3 } & $\begin{array}{l}\text { Benefits Clearly Outweigh Risks } \\
\text { and Burden or Risks and Burden } \\
\text { Clearly Outweigh Benefits }\end{array}$ & $\begin{array}{c}\text { Benefits Finely Balanced } \\
\text { With Risks and Burden }\end{array}$ \\
\hline High & Strong & Weak \\
Moderate & Strong & Weak \\
Low & Strong & Weak \\
\hline \multicolumn{2}{|r|}{ Insufficient evidence to determine net benefits or risks } \\
\hline
\end{tabular}

* Adopted from the classification developed by the GRADE (Grading of Recommendations Assessment, Development, and Evaluation) workgroup.

acute gout from 5 randomized, controlled trials (RCTs) $(17,18,47-49)$. High-quality evidence showed that colchicine reduces pain in patients with acute gout (17, 18). Moderate-quality evidence from 1 study (17) showed that lower doses of colchicine (initial dose of $1.2 \mathrm{mg}$ followed by $0.6 \mathrm{mg}$ after 1 hour) are as effective as higher doses $(1.2 \mathrm{mg}$ followed by $0.6 \mathrm{mg} / \mathrm{h}$ for 6 hours) for reducing pain and are associated with fewer gastrointestinal adverse effects (for diarrhea: $77 \%$ in the high-dose group, $23 \%$ in the low-dose group, and $14 \%$ in the placebo group). Colchicine is also associated with other gastrointestinal adverse effects, including nausea, vomiting, cramps, and pain (50), and is infrequently associated with headache and fatigue.

\section{Nonsteroidal Anti-inflammatory Drugs}

One placebo-controlled trial of tenoxicam $(40 \mathrm{mg}$ once daily) showed that it reduces pain but is no different from placebo for swelling in patients with acute gout. High-quality evidence from 1 RCT (38) and observational data showed that nonsteroidal antiinflammatory drugs (NSAIDs) reduce pain in patients with acute gout. These drugs have known antiinflammatory activity and have been shown to reduce pain in many conditions. Further, they have been successfully used to prevent gout flares during uratelowering therapy. The main harms of NSAIDs are gastrointestinal adverse effects ranging from minor (dyspepsia) to serious (perforations, ulcers, and bleeding). Long-term use of higher doses can cause chronic renal insufficiency.

\section{Corticosteroids}

There were no placebo-controlled trials of oral corticosteroids. High-quality indirect evidence suggested that systemic corticosteroids reduce pain in patients with acute gout. Although there was no direct evidence assessing the efficacy of systemic corticosteroids to treat gout, corticosteroids have a proven antiinflammatory effect and were shown to be equivalent to NSAIDs for various outcomes in 6 RCTs $(15,24,28,35$, $36,40)$. Long-term use of corticosteroids is associated with adverse effects that are dose- and durationdependent and affect almost all organs of the body.
These include dysphoria, mood disorders, elevation of blood glucose levels, immune suppression, and fluid retention.

\section{Animal-Derived Corticotropin}

Although no placebo-controlled RCTs were identified, moderate-quality evidence suggested that parenteral corticotropin reduces pain in patients with acute gout. Corticotropin has known anti-inflammatory activity, and evidence from 2 comparative effectiveness trials showed that it was similar to NSAIDs (29) and corticosteroids (30) for various outcomes. Harms of corticotropin are likely similar to those for corticosteroids, due to similar biologic activities.

\section{Comparative Effectiveness (Benefits and Harms) of Pharmacologic Treatments NSAIDs Versus NSAIDs}

Moderate-quality evidence from 16 RCTs $(13,14$ $16,19-23,25-27,31-34,39)$ showed no clinically important differences in comparisons of different types of NSAIDs with one another in patients with gout.

\section{Corticosteroids Versus Corticotropin}

One RCT (30) showed no difference in the duration of acute gout attacks or the number of joints affected when comparing corticotropin with intramuscular triamcinolone.

\section{Corticosteroids Versus NSAIDs}

Six RCTs $(15,24,28,35,36,40)$ showed no difference in time to resolution of symptoms, clinical joint status at follow-up, or pain reduction between NSAIDs and corticosteroids. However, NSAIDs were associated with more frequent gastrointestinal, nongastrointestinal, and serious adverse events (46).

\section{NSAIDs Versus Selective Cyclooxygenase-2 Inhibitors}

Four RCTs showed no difference in pain, joint swelling, global improvement, and health-related quality of life when comparing NSAIDs and cyclooxygenase-2 inhibitors. Cyclooxygenase-2 inhibitors were associated with fewer total adverse events (38\% vs. $60 \%$ ) and fewer withdrawals due to adverse events ( $3 \%$ vs. $8 \%$ ) than NSAIDs.

\section{NSAIDs Versus Parenteral Corticotropin}

One RCT (29) showed that time to pain relief was shorter with corticotropin than with indomethacin, 50 mg 4 times daily (3 vs. 24 hours). No adverse effects were reported for patients treated with corticotropin, whereas NSAIDs were associated with abdominal discomfort or dyspepsia (55\%) and headache (38\%).

\section{Effectiveness Based on Subgroups}

No studies presented effectiveness data for subgroups based on sex, acute episode, history of gout, HLA-B*5801 status, tophi, or comorbidities. 


\section{Dietary And Lifestyle Management OF GouT}

\section{Effectiveness (Benefits and Harms) of Dietary and Lifestyle Management}

Evidence from 4 systematic reviews of RCTs (42, 51-53) and 2 new RCTs $(54,55)$ was insufficient to determine the efficacy of dietary therapies on symptomatic outcomes. Low-quality evidence from 1 systematic review (52) of 13 trials with high heterogeneity showed that vitamin $\mathrm{C}$ supplementation reduced serum urate levels $(-20.8 \mu \mathrm{mol} / \mathrm{L}[-0.35 \mathrm{mg} / \mathrm{dL}][95 \% \mathrm{Cl},-39.3$ to $-1.8 \mu \mathrm{mol} / \mathrm{L}\{-0.66$ to $-0.03 \mathrm{mg} / \mathrm{dL}\}])$.

Low-quality evidence from 1 study (54) showed that gout-specific counseling about dietary changes (such as reducing intake of red meat, shellfish, and yeast-rich foods and increasing intake of low-fat dairy products, vegetables, and cherries) is not more effective than general dietary counseling (promoting weight loss and reducing alcohol intake) for reducing serum urate levels in patients with gout.

Evidence from 5 systematic reviews $(41,56-59)$ was insufficient to determine the effectiveness of traditional Chinese medicine, including herbs and acupuncture, on symptomatic outcomes.

\section{Effectiveness Based on Subgroups}

There were no effectiveness data based on sex, acute episode, history of gout, HLA-B ${ }^{\star 5801}$ status, tophi, or comorbidities.

\section{Pharmacologic Management of Hyperuricemia to Reduce RecurRent Gout or Other Health Outcomes Effectiveness (Benefits and Harms) of Pharmacologic Therapy}

High-quality evidence from 4 RCTs (60-63) showed that urate-lowering therapy (allopurinol and febuxostat) reduces serum urate levels. High-quality evidence from 2 RCTs showed that urate-lowering therapy does not reduce the risk for gout attacks within the first 6 months. There were no long-term RCTs that compared gout flares between patients treated versus those not treated with urate-lowering therapy. Observational evidence from follow-up of 2 RCTs (64) and several retrospective cohort studies (65-67) consistently showed that patients with lower serum urate levels had fewer flares than those with higher levels. Together with the fact that urate crystalizes at a level greater than about $416 \mu \mathrm{mol} / \mathrm{L}$ ( $7 \mathrm{mg} / \mathrm{dL})$, the evidence is graded as moderate-quality that longer-term urate-lowering therapy ( $>1$ year) reduces gout flares. We consider the magnitude of this reduction uncertain.

The most common adverse event with allopurinol is rash. Most of the serious adverse effects associated with allopurinol ( $\geq 40$ years of history) are rare, mild, and reversible; however, fatal hypersensitivity reactions have also been reported with the drug (68). Persons with the HLA-B $\star 5801$ haplotype, which is prevalent in
Asian persons (including those of Han Chinese and Thai descent) and in Korean persons with stage 3 or worse chronic kidney disease, may have an increased risk for serious adverse effects with allopurinol (69-75). The most commonly reported adverse events from limited trials of febuxostat were abdominal pain, diarrhea, and musculoskeletal pain. There is more uncertainty about the harms of febuxostat because there are no large data-based studies and the clinical experience with this drug is more limited than with older uratelowering medications.

\section{Comparative Effectiveness (Benefits and Harms) of Pharmacologic Therapy}

Evidence was gathered from 4 high-quality systematic reviews (76-79) comparing the efficacy of febuxostat and allopurinol. Gout flare incidence was higher at high doses of febuxostat (120 or $240 \mathrm{mg} / \mathrm{d}$ ) compared with allopurinol (100 to $300 \mathrm{mg} / \mathrm{d}$ ). There was no difference in gout flare incidence between lower doses of febuxostat (40 or $80 \mathrm{mg} / \mathrm{d}$ ) and allopurinol (100 to 300 $\mathrm{mg} / \mathrm{d}$ ). The evidence was inconclusive with regard to changes in tophi. High-quality evidence from 1 RCT showed no difference between febuxostat $(40 \mathrm{mg} / \mathrm{d})$ and allopurinol $(300 \mathrm{mg} / \mathrm{d})$ for decreasing serum urate levels, and $80 \mathrm{mg}$ of febuxostat per day was more effective than either 40 or $300 \mathrm{mg}$ of allopurinol per day for decreasing serum urate levels (62).

Evidence comparing harms between allopurinol and febuxostat was inconclusive, partly because of limited information about the adverse effects of febuxostat.

\section{Prophylactic Therapy Against Acute Gout Flares in Patients Initiating Serum Urate-Lowering Therapy}

High-quality evidence from 1 RCT (47) and observational evidence from $3 \mathrm{RCTs}(60-62)$ showed that use of low doses of colchicine $(0.6 \mathrm{mg}$ twice daily) or NSAIDs for prophylactic therapy reduces risk for gout attacks in patients initiating urate-lowering therapy. Moderate-quality evidence from 1 RCT (59) and indirect evidence from 3 RCTs $(51,52,80)$ suggests that use of prophylactic colchicine or NSAIDs for longer durations (>8 weeks) is more effective at reducing gout flares than use for shorter durations in patients initiating serum urate-lowering therapy.

\section{Effectiveness Based on Subgroups}

Low-quality evidence from subgroup analyses of 1 RCT (81) showed no difference in the efficacy of febuxostat or allopurinol for decreasing serum urate levels based on age (82) or race (83). Evidence was insufficient for sex, baseline tophi, baseline serum urate level, or comorbidities. No studies presented data on HLA-B*5801 status.

\section{Monitoring Serum Urate Levels in Patients With Gout}

No studies have assessed the effect of monitoring serum urate levels in patients with gout on adherence or treatment outcomes. 
Evidence was insufficient to conclude whether the benefits of escalating urate-lowering therapy to reach a serum urate target ("treat to target") outweigh the harms associated with repeated monitoring and medication escalation. There is no evidence from an experimental study that examined the health outcomes of treating to one serum urate level versus another, nor is there a trial comparing a strategy of basing treatment on attaining a specific urate level versus basing treatment on reduction in symptoms (such as gout flares). The evidence review looked for other studies to evaluate whether achieving lower subsequent serum urate levels (<297 vs. 297 to $416 \mu \mathrm{mol} / \mathrm{L}[<5$ vs. 5 to $7 \mathrm{mg} /$ $\mathrm{dL}]$ ) is associated with decreased risk for recurrent gout attack, progression to chronic arthritis or disability, resolution of tophi, or other clinical outcomes. A post hoc observational analysis (64) from 2 large trials $(60,61)$ showed that patients who attained a urate level less than $357 \mu \mathrm{mol} / \mathrm{L}(<6.0 \mathrm{mg} / \mathrm{dL})$ had fewer gout flares at 12 months than those who did not (about $5 \%$ of patients with serum urate level $<6.0 \mathrm{mg} / \mathrm{dL}$ vs. $10 \%$ to $15 \%$ of those with levels $>6.0 \mathrm{mg} / \mathrm{dL})$. Eight other retrospective cohort studies $(65,67,84-89)$ found similar associations. Although these studies showed an association between lower urate levels and fewer gout flares, they did not establish that urate-lowering therapy rather than other underlying patient characteristics caused the reduction in flares. Further, even if uratelowering therapy does reduce gout flares, these studies do not help us understand the tradeoff between the magnitude of benefit and the harms and costs incurred by treatment and monitoring. Thus, we remain uncertain about the value of a treat-to-target strategy compared with a strategy of basing treatment intensity on minimizing symptoms.

\section{Discontinuation of Pharmacologic Treatment of Acute or Chronic Gout Treatment of Hyperuricemia}

Evidence was insufficient to determine criteria for discontinuing urate-lowering therapy. Three prospective observational studies (90-92) showed that uratelowering therapy can be discontinued without increasing the risk for acute gout attacks in some patients, but there were no applicable RCTs. One cohort study showed that urate-lowering therapy can be discontinued in asymptomatic patients who have maintained serum urate levels less than $416 \mu \mathrm{mol} / \mathrm{L}(<7 \mathrm{mg} / \mathrm{dL})$ after 5 years of treatment and in whom annual serum urate levels remained below this level (91).

\section{Prophylaxis During Urate-Lowering Therapy}

Moderate-quality indirect evidence from comparisons of 3 RCTs (60-62) suggests continuing prophylaxis during urate-lowering therapy using low-dose colchicine or low-dose NSAIDs for more than 8 weeks to prevent acute gout flares. Evidence showed that the rate of acute gout flares approximately doubled when anti-inflammatory prophylaxis was discontinued after 8 weeks $(60,61)$. Acute gout flares did not increase in a trial that continued prophylaxis for 6 months (62).

\section{SUMMARY}

Evidence was insufficient for gout-specific dietary advice or therapies (such as reduced intake of red meat, fructose, and alcohol) to improve symptomatic outcomes. Although 1 systematic review (52) and 1 RCT (55) found that dietary changes reduced urate levels, no study examined the effect of any dietary intervention on clinical outcomes, such as acute gout flares. Lowquality evidence showed that gout-specific dietary advice is similar to general dietary counseling with regard to the effect on serum urate levels in patients with gout.

Evidence from placebo-controlled trials and headto-head comparisons showed that colchicine, NSAIDs, corticosteroids (high-quality evidence for each), and animal-derived corticotropin (moderate-quality evidence) are effective for reducing pain in patients with acute gout. Lower doses of colchicine are as effective as higher doses and are associated with fewer adverse effects. Evidence also showed that NSAIDs are effective as a class, regardless of choice of the individual drug. Harms associated with colchicine include gastrointestinal adverse events, such as diarrhea, nausea, cramps, and vomiting. Nonsteroidal anti-inflammatory drugs are associated with dyspepsia and potential gastrointestinal perforations, ulcers, and bleeding. Corticosteroids are associated with mood disorders and dysphoria, elevation of blood glucose levels, immune suppression, and fluid retention. Corticotropin is less well-studied; thus, harms are largely unknown but are likely to be similar to those associated with corticosteroids due to similar biologic activity. Fair prices are highest for corticotropin, and colchicine is currently the most expensive nonbiologic.

High-quality evidence showed that urate-lowering therapy does not reduce the risk for acute gout attacks in the first 6 months in patients with gout. Observational evidence showed that patients who attained lower urate levels after 1 year of urate-lowering therapy had fewer gout flares. High-quality evidence showed no difference between lower doses of febuxostat and allopurinol for gout flares. The most common adverse events are rash with allopurinol and abdominal pain, diarrhea, and musculoskeletal pain with febuxostat. Febuxostat is associated with higher costs than allopurinol. High-quality evidence shows that prophylactic therapy with low-dose colchicine or low-dose NSAIDs effectively reduces acute gout flares in patients initiating urate-lowering therapy, and moderate-quality evidence supports continuing prophylactic therapy for more than 8 weeks. Evidence was insufficient about whether urate-lowering therapy can be safely discontinued after 5 years.

Evidence is insufficient for monitoring of serum urate levels in patients with gout.

Target thresholds for serum urate levels rely on the chemistry of urate, which is soluble up to a concentra- 
tion of about $404 \mu \mathrm{mol} / \mathrm{L}(6.8 \mathrm{mg} / \mathrm{dL})$, above which precipitation may occur. However, this threshold is not absolute because patients with higher serum urate levels may still be asymptomatic, and some may have acute flares below this threshold. Although there is an association between lower urate levels and fewer gout flares, the extent to which use of urate-lowering therapy to achieve various targets can reduce gout flares is uncertain. The Figure summarizes the recommendations and clinical considerations.

\section{RECOMMENDATIONS}

Recommendation 1: $A C P$ recommends that clinicians choose corticosteroids, nonsteroidal antiinflammatory drugs (NSAIDs), or colchicine to treat patients with acute gout. (Grade: strong recommendation, high-quality evidence)

High-quality evidence showed that corticosteroids, NSAIDs, and colchicine are effective treatments to reduce pain in patients with acute gout. Gout symptoms are mostly caused by inflammatory reaction to the deposition of urate crystals, which results from an increase in serum urate level above its saturation point in the blood. Hence, most medications that are used to target anti-inflammatory responses help to reduce the symptoms. Contraindications, harms, and costs vary among treatments.

Corticosteroids should be considered as first-line therapy in patients without contraindications because they are generally safer and a low-cost treatment option. Steroids are among the most effective antiinflammatory medications available and have been shown to be as effective as NSAIDs for managing gout, with fewer adverse effects. Prednisolone at a dose of 35 mg for 5 days has been successfully used to treat acute gout (15). Adverse effects associated with long-term use of corticosteroids include dysphoria, mood disorders, elevation of blood glucose levels, immune suppression, and fluid retention. Corticosteroids are contraindicated in patients with systemic fungal infections or known contraindications.

Moderate-quality evidence showed no difference between different types of NSAIDs, including indomethacin. Adverse effects associated with NSAIDs include dyspepsia and potential gastrointestinal perforations, ulcers, and bleeding. Patients in whom NSAIDs may be contraindicated include those with renal disease, heart failure, or cirrhosis. Although indomethacin is commonly considered as the first-line NSAID for treatment of acute gout, there is no evidence that it is more efficacious than other NSAIDs, such as naproxen and ibuprofen.

A generic formulation of colchicine is now available for gout treatment, but it is still more expensive than NSAIDs or corticosteroids. Adverse effects associated with colchicine include gastrointestinal issues (such as diarrhea, nausea, vomiting, cramps, and pain) and, infrequently, headache and fatigue. Colchicine is contraindicated in patients with renal or hepatic impairment who are using potent cytochrome P450 3A4 inhibitors or P-glycoprotein inhibitors.

Recommendation 2: ACP recommends that clinicians use low-dose colchicine when using colchicine to treat acute gout. (Grade: strong recommendation, moderate-quality evidence)

Moderate-quality evidence suggests that lower doses of colchicine $(1.2 \mathrm{mg}$ followed by $0.6 \mathrm{mg} 1$ hour later) are as effective as higher doses (1.2 $\mathrm{mg}$ followed by $0.6 \mathrm{mg} / \mathrm{h}$ for 6 hours) at reducing pain and are associated with fewer gastrointestinal adverse effects.

Recommendation 3: ACP recommends against initiating long-term urate-lowering therapy in most patients after a first gout attack or in patients with infrequent attacks. (Grade: strong recommendation, moderate-quality evidence)

Although evidence supports the benefits of using urate-lowering therapy for shorter durations to reduce gout flares, the benefits of long-term use $(\geq 12$ months) in patients with a single or infrequent gout attacks ( $<2$ per year) have not been studied. Uratelowering therapy is not necessary in cases where the patient would have no or infrequent recurrences. In cases of recurrent gout ( $\geq 2$ episodes per year) or problematic gout (for example, gout associated with tophi, chronic renal disease, or urolithiasis), shared decision making with the patient is warranted to review possible harms and benefits of urate-lowering therapy.

Recommendation 4: ACP recommends that clinicians discuss benefits, harms, costs, and individual preferences with patients before initiating urate-lowering therapy, including concomitant prophylaxis, in patients with recurrent gout attacks. (Grade: strong recommendation, moderate-quality evidence)

After resolution of acute gout, some patients may have recurrent episodes. Some patients have no or few attacks over many years, whereas others have more frequent attacks. Although evidence is inadequate to predict which patients will have more problems, those with higher serum urate levels (especially $>476 \mu \mathrm{mol} / \mathrm{L}$ [ $>8$ $\mathrm{mg} / \mathrm{dL}]$ ) are at greater risk. Some may prefer to initiate long-term therapy to prevent future gout attacks, whereas others may prefer to treat flares if they occur. Patients who decide not to initiate urate-lowering therapy can revisit their decision if they have multiple recurrences of acute gout.

Febuxostat $(40 \mathrm{mg} / \mathrm{d})$ and allopurinol $(300 \mathrm{mg} / \mathrm{d})$ are equally effective at decreasing serum urate levels. However, these drugs are associated with adverse effects, including rash with allopurinol and abdominal pain, diarrhea, and musculoskeletal pain with febuxostat.

Data on the most appropriate duration of uratelowering therapy are insufficient. Moderate- to highquality evidence suggests that urate-lowering therapy reduces the risk for acute gout attacks after 1 year, but not within the first 6 months of treatment. 
Figure. Summary of the American College of Physicians guideline on management of acute and recurrent gout.

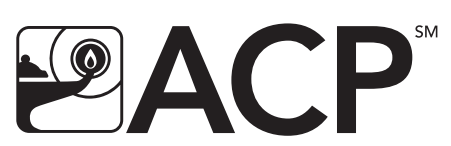

American College of Physicians

Leading Internal Medicine, Improving Lives

Summary of the American College of Physicians Guideline on Management of Acute and Recurrent Gout

\begin{tabular}{|c|c|}
\hline Disease/Condition & Acute or recurrent gout \\
\hline Target Audience & All clinicians \\
\hline Target Patient Population & Adults with acute or recurrent gout \\
\hline Treatments Evaluated & $\begin{array}{l}\text { Dietary interventions; other lifestyle measures (smoking cessation, exercise, hydration); dietary supplements and alternative } \\
\text { treatments (vitamin C supplementation, traditional Chinese medicine); pharmacologic agents, including anti-inflammatory drugs } \\
\text { (NSAIDs, corticosteroids), colchicine, and urate-lowering therapies (xanthine oxidase inhibitors, uricosuric agents); combination } \\
\text { drug therapies; or combination drug and dietary or alternative treatments }\end{array}$ \\
\hline Outcomes Evaluated & $\begin{array}{l}\text { Efficacy, including short-term (pain, joint swelling, and tenderness) and long-term (serum urate levels, pain, joint swelling, and } \\
\text { tenderness) outcomes; activities of daily living; patient global assessment; recurrence; intermediate outcome of serum urate } \\
\text { levels; and harms }\end{array}$ \\
\hline Benefits & $\begin{array}{l}\text { Acute gout treatment (colchicine, NSAIDs, corticosteroids, corticotropin): reduction of pain } \\
\text { Prophylaxis during serum urate-lowering therapy (low-dose colchicine and low-dose NSAIDs): reduced acute gout flares }\end{array}$ \\
\hline $\begin{array}{l}\text { Harms and Adverse } \\
\text { Effects }\end{array}$ & $\begin{array}{l}\text { Colchicine: gastrointestinal adverse effects, such as diarrhea, nausea, cramps, and vomiting } \\
\text { NSAIDs: dyspepsia and potential gastrointestinal perforations, ulcers, and bleeding } \\
\text { Corticosteroids: mood disorders and dysphoria, elevation of blood glucose levels, immune suppression, and fluid retention } \\
\text { Corticotropin: unknown, but probably similar to those of corticosteroids } \\
\text { Serum urate-lowering therapy: } \\
\text { Febuxostat: abdominal pain, diarrhea, and musculoskeletal pain } \\
\text { Allopurinol: rash and reactions (including potentially serious ones) }\end{array}$ \\
\hline Recommendations & $\begin{array}{l}\text { Recommendation 1: ACP recommends that clinicians choose corticosteroids, nonsteroidal anti-inflammatory drugs (NSAIDs), } \\
\text { or colchicine to treat patients with acute gout. (Grade: strong recommendation, high-quality evidence) }\end{array}$ \\
\hline
\end{tabular}
or colchicine to treat patients with acute gout. (Grade: strong recommendation, high-quality evidence)

High-quality evidence showed that corticosteroids, NSAIDs, and colchicine are effective treatments to reduce pain in patients with acute gout.

Recommendation 2: ACP recommends that clinicians use low-dose colchicine when using colchicine to treat acute gout. (Grade: strong recommendation, moderate-quality evidence)

Lower doses of colchicine $(1.2 \mathrm{mg}$ followed by $0.6 \mathrm{mg} 1 \mathrm{~h}$ later) are as effective as higher doses $(1.2 \mathrm{mg}$ followed by $0.6 \mathrm{mg} / \mathrm{h}$ for $6 \mathrm{~h}$ ) at reducing pain and are associated with fewer gastrointestinal adverse effects.

Recommendation 3: ACP recommends against initiating long-term urate-lowering therapy in most patients after a first gout attack or in patients with infrequent attacks. (Grade: strong recommendation, moderate-quality evidence)

Although evidence supports the benefits of using urate-lowering therapy for shorter durations to reduce gout flares, the benefits of long-term use $(\geq 12 \mathrm{mo}$ ) in patients with a single or infrequent gout attacks have not been studied.

Recommendation 4: ACP recommends that clinicians discuss benefits, harms, costs, and individual preferences with patients before initiating urate-lowering therapy, including concomitant prophylaxis, in patients with recurrent gout attacks. (Grade: strong recommendation, moderate-quality evidence)

Upon resolution of acute gout, some patients have no or few attacks over many years, whereas others have more frequent or recurrent attacks. Febuxostat $(40 \mathrm{mg} / \mathrm{d})$ and allopurinol $(300 \mathrm{mg} / \mathrm{d})$ are equally effective at decreasing serum urate levels, and prophylactic therapy with low-dose colchicine or low-dose NSAIDs reduces the risk for acute gout attacks in patients initiating urate-lowering therapy.

\begin{tabular}{l|l}
\hline High-Value Care & Clinicians should select from among corticosteroids, NSAIDs, or colchicine as first-line therapy on the basis of costs when
\end{tabular} treating patients with acute gout who do not have contraindications to these drugs. Colchicine, including the current generic version, is the most expensive of these medications. Clinicians should also carefully consider and discuss the benefits, harms, and costs of initiating urate-lowering therapy with the patient immediately after an episode of acute gout and if the patient has recurrent flares. The intensity of urate-lowering therapy and monitoring of urate levels should be based on discussions with individual patients, given the uncertainties of different treatment strategies.

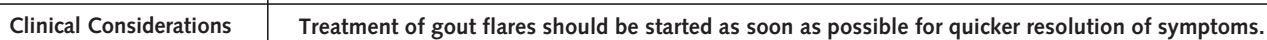

Not all patients with elevated serum urate levels have gout symptoms or recurrent gout attacks, and some patients with urate levels below the commonly identified threshold of $357 \mu \mathrm{mol} / \mathrm{L}(6 \mathrm{mg} / \mathrm{dL})$ may have symptoms.

Allopurinol is associated with an increased risk for serious adverse events in persons with the HLA-B*5801 haplotype, which is prevalent in certain Asian populations.

NSAID = nonsteroidal anti-inflammatory drug. 
High-quality evidence showed that prophylactic therapy with low-dose colchicine or low-dose NSAIDs reduces the risk for acute gout attacks in patients initiating urate-lowering therapy. Moderate-quality evidence also showed that continuing prophylactic treatment for more than 8 weeks was more effective than shorter durations to help prevent gout flares in patients initiating urate-lowering therapy.

\section{Areas of Inconclusive Evidence Treatment Strategy for Patients With Gout Receiving Urate-Lowering Therapy}

A paradigm has developed that monitoring serum urate levels and targeting therapy to achieve a specific urate level (treat to target) reduces acute gout attacks and subsequent joint damage. An alternative strategy bases the intensity of urate-lowering treatment on the goal of avoiding recurrent gout attacks ("treat to avoid symptoms"), with no monitoring of urate levels. Comparative effectiveness studies that evaluate the incremental benefits and harms of a treat-to-target strategy over a treat-to-avoid-symptoms strategy should be a priority.

\section{Effect of Urate-Lowering Treatment on Adverse Health Outcomes Beyond Acute Gout}

The importance of decreasing urate levels to prevent adverse health outcomes beyond acute gout is uncertain.

\section{Duration of Urate-Lowering Treatment}

Insufficient evidence suggests that some patients with annual urate levels less than $416 \mu \mathrm{mol} / \mathrm{L}(<7 \mathrm{mg} /$ $\mathrm{dL}$ ) may be able to stop urate-lowering treatment after about 5 years.

\section{Treatment in Different Patient Groups}

Evidence is insufficient to determine whether treatment of patients with gout should vary according to such variables as patient demographic characteristics, comorbidities, gout severity, clinical presentation, or laboratory values.

\section{Effect of Dietary Treatments}

Although many patients are counseled to change various dietary factors or supplements, we found insufficient evidence to recommend these changes.

\section{Long-Term Effects of Febuxostat}

Although patients may be prescribed this medication for longer periods, we have little evidence about its long-term benefits or harms.

\section{High-Value Care}

Clinicians should select from among corticosteroids, NSAIDs, or colchicine as first-line therapy on the basis of costs when treating patients with acute gout who do not have contraindications to one of these drugs. Colchicine, including the recently introduced generic version, is the most expensive of these medications. Clinicians should also carefully consider and discuss the benefits, harms, and costs of initiating urate- lowering therapy with the patient after an episode of acute gout and if the patient has recurrent flares. The intensity of urate-lowering therapy and monitoring of urate levels should be based on discussions with individual patients, given the uncertainties of different treatment strategies.

From the American College of Physicians and University of Pennsylvania Health System, Philadelphia, Pennsylvania, and University of North Carolina School of Medicine, Chapel Hill, North Carolina.

Note: Clinical practice guidelines are "guides" only and may not apply to all patients and all clinical situations. Thus, they are not intended to override clinicians' judgment. All ACP clinical practice guidelines are considered automatically withdrawn or invalid 5 years after publication, or once an update has been issued.

Disclaimer: The authors of this article are responsible for its contents, including any clinical or treatment recommendations.

Financial Support: Financial support for the development of this guideline comes exclusively from the ACP operating budget.

Disclosures: Dr. Barry reports grants and personal fees from the Informed Medical Decisions Foundation and Healthwise outside the submitted work. Dr. Boyd reports royalties from UpToDate outside the submitted work. Authors not named here have disclosed no conflicts of interest. Authors followed the policy regarding conflicts of interest described at www .annals.org/aim/article/745942. Disclosures can also be viewed at www.acponline.org/authors/icmje/ConflictOf InterestForms.do?msNum=M16-0570. All financial and intellectual disclosures of interest were declared, and potential conflicts were discussed and managed. Dr. Manaker was recused from voting on this guideline because of an active indirect financial conflict. Dr. McLean was recused from voting on this guideline because of an inactive direct financial conflict. A record of disclosures of interest and management of conflicts of interest is kept for each Clinical Guidelines Committee meeting and conference call and can be viewed at www.acponline.org/about-acp/who-we-are/leadership /committees-boards-councils/clinical-guidelines-committee /disclosure-of-interests-for-clinical-guidelines-committee.

Requests for Single Reprints: Amir Qaseem, MD, PhD, MHA, American College of Physicians, 190 N. Independence Mall West, Philadelphia, PA 19106; e-mail, aqaseem@acponline .org.

Current author addresses and author contributions are available at www.annals.org.

\section{References}

1. Choi HK, Atkinson K, Karlson EW, Curhan G. Obesity, weight change, hypertension, diuretic use, and risk of gout in men: the Health Professionals Follow-up Study. Arch Intern Med. 2005;165: 742-8. [PMID: 15824292] 
2. Choi HK, Atkinson K, Karlson EW, Willett W, Curhan G. Alcohol intake and risk of incident gout in men: a prospective study. Lancet. 2004;363:1277-81. [PMID: 15094272]

3. Choi HK, Atkinson K, Karlson EW, Willett W, Curhan G. Purine-rich foods, dairy and protein intake, and the risk of gout in men. N Engl J Med. 2004;350:1093-103. [PMID: 15014182]

4. Krishnan E. Chronic kidney disease and the risk of incident gout among middle-aged men: a seven-year prospective observational study. Arthritis Rheum. 2013;65:3271-8. [PMID: 23982888] doi:10 .1002/art.38171

5. Zhu Y, Pandya BJ, Choi H. Prevalence of gout in the U.S. general population: the National Health and Nutrition Examination Survey (NHANES) 2007-2008. Value Health. 2010;13:A304.

6. Li C, Martin BC, Cummins DF, Mon Andrews L, Frech-Tamas F, Yadao AM. Ambulatory resource utilization and cost for gout in United States. Am J Pharm Benefits. 2013;5:e46-54.

7. Shekelle PG, Newberry SJ, FitzGerald JD, Motala A, O'Hanlon CE, Tariq A, et al. Management of gout: a systematic review in support of an American College of Physicians clinical practice guideline. Ann Intern Med. 2017;166:37-51. doi:10.7326/M16-0461

8. Shekelle PG, FitzGerald J, Newberry SJ, Motala A, O'Hanlon CE, Okunogbe A, et al. Management of Gout. Comparative Effectiveness Review no. 176. (Prepared by the RAND Southern California Evidence-based Practice Center under contract 290-2012-00006-I.) AHRQ publication no. 16-EHC017-EF. Rockville: Agency for Healthcare Research and Quality; March 2017. Accessed at www .effectivehealthcare.ahrq.gov/reports/final.cfm on 12 October 2016. 9. Qaseem A, McLean R, Starkey M, Forciea MA; Clinical Guidelines Committee of the American College of Physicians. Diagnosis of acute gout: a clinical practice guideline from the American College of Physicians. Ann Intern Med. 2017;166:52-7. doi:10.7326 /M16-0569

10. Qaseem A, Snow V, Owens DK, Shekelle P; Clinical Guidelines Committee of the American College of Physicians. The development of clinical practice guidelines and guidance statements of the American College of Physicians: summary of methods. Ann Intern Med. 2010;153:194-9. [PMID: 20679562] doi:10.7326/0003-4819 -153-3-201008030-00010

11. Agency for Healthcare Research and Quality. Methods Guide for Effectiveness and Comparative Effectiveness Reviews. AHRQ publication no. 10(14)-EHC063-EF. Rockville: Agency for Healthcare Research and Quality; 2014.

12. Hill AB. The environment and disease: association or causation? Proc R Soc Med. 1965;58:295-300. [PMID: 14283879]

13. Maccagno A, Di Giorgio E, Romanowicz A. Effectiveness of etodolac ('Lodine') compared with naproxen in patients with acute gout. Curr Med Res Opin. 1991;12:423-9. [PMID: 1838075]

14. Schumacher HR, Berger MF, Li-Yu J, Perez-Ruiz F, Burgos-Vargas $\mathrm{R}, \mathrm{Li}$ C. Efficacy and tolerability of celecoxib in the treatment of acute gouty arthritis: a randomized controlled trial. J Rheumatol. 2012;39: 1859-66. [PMID: 22859357] doi:10.3899/jrheum.110916

15. Janssens $H J$, Janssen $M$, van de Lisdonk $E H$, van Riel $P L$, van Weel C. Use of oral prednisolone or naproxen for the treatment of gout arthritis: a double-blind, randomised equivalence trial. Lancet. 2008;371:1854-60. [PMID: 18514729] doi:10.1016/S0140 -6736(08)60799-0

16. Li T, Chen SL, Dai Q, Han XH, Li ZG, Wu DH, et al. Etoricoxib versus indomethacin in the treatment of Chinese patients with acute gouty arthritis: a randomized double-blind trial. Chin Med J (Engl). 2013;126:1867-71. [PMID: 23673101]

17. Terkeltaub RA, Furst DE, Bennett K, Kook KA, Crockett RS, Davis MW. High versus low dosing of oral colchicine for early acute gout flare: twenty-four-hour outcome of the first multicenter, randomized, double-blind, placebo-controlled, parallel-group, dose-comparison colchicine study. Arthritis Rheum. 2010;62:1060-8. [PMID: 20131255] doi:10.1002/art.27327

18. Ahern MJ, Reid C, Gordon TP, McCredie M, Brooks PM, Jones M. Does colchicine work? The results of the first controlled study in acute gout. Aust N Z J Med. 1987;17:301-4. [PMID: 3314832]
19. Cheng TT, Lai HM, Chiu CK, Chem YC. A single-blind, randomized, controlled trial to assess the efficacy and tolerability of rofecoxib, diclofenac sodium, and meloxicam in patients with acute gouty arthritis. Clin Ther. 2004;26:399-406. [PMID: 15110132]

20. Shrestha M, Morgan DL, Moreden JM, Singh R, Nelson M, Hayes JE. Randomized double-blind comparison of the analgesic efficacy of intramuscular ketorolac and oral indomethacin in the treatment of acute gouty arthritis. Ann Emerg Med. 1995;26:682-6. [PMID: 7492036]

21. Altman RD, Honig S, Levin JM, Lightfoot RW. Ketoprofen versus indomethacin in patients with acute gouty arthritis: a multicenter, double blind comparative study. J Rheumatol. 1988;15:1422-6. [PMID: 3058974]

22. Eberl R, Dunky A. Meclofenamate sodium in the treatment of acute gout. Results of a double-blind study. Arzneimittelforschung. 1983;33:641-3. [PMID: 6349648]

23. Ruotsi A, Vainio U. Treatment of acute gouty arthritis with proquazone and indomethacin. A comparative, double-blind trial. Scand J Rheumatol Suppl. 1978:15-7. [PMID: 356235]

24. Alloway JA, Moriarty MJ, Hoogland YT, Nashel DJ. Comparison of triamcinolone acetonide with indomethacin in the treatment of acute gouty arthritis. J Rheumatol. 1993;20:111-3. [PMID: 8441139] 25. Lederman R. A double-blind comparison of etodolac and high doses of naproxen in the treatment of acute gout. Adv Ther. 1990; 7:344-54.

26. Schumacher HR Jr, Boice JA, Daikh DI, Mukhopadhyay S, Malmstrom K, Ng J, et al. Randomised double blind trial of etoricoxib and indometacin in treatment of acute gouty arthritis. BMJ. 2002;324: 1488-92. [PMID: 12077033]

27. Rubin BR, Burton R, Navarra S, Antigua J, Londoño J, Pryhuber $K G$, et al. Efficacy and safety profile of treatment with etoricoxib 120 $\mathrm{mg}$ once daily compared with indomethacin $50 \mathrm{mg}$ three times daily in acute gout: a randomized controlled trial. Arthritis Rheum. 2004; 50:598-606. [PMID: 14872504]

28. Man CY, Cheung IT, Cameron PA, Rainer TH. Comparison of oral prednisolone/paracetamol and oral indomethacin/paracetamol combination therapy in the treatment of acute goutlike arthritis: a double-blind, randomized, controlled trial. Ann Emerg Med. 2007; 49:670-7. [PMID: 17276548]

29. Axelrod D, Preston S. Comparison of parenteral adrenocorticotropic hormone with oral indomethacin in the treatment of acute gout. Arthritis Rheum. 1988;31:803-5. [PMID: 2454635]

30. Siegel LB, Alloway JA, Nashel DJ. Comparison of adrenocorticotropic hormone and triamcinolone acetonide in the treatment of acute gouty arthritis. J Rheumatol. 1994;21:1325-7. [PMID: 7966077] 31. Douglas G, Thompson M. A comparison of phenylbutazone and flufenamic acid in the treatment of acute gout. Ann Phys Med. 1970; 10:275-80. [PMID: 4913482]

32. Butler RC, Goddard DH, Higgens CS, Hollingworth P, Pease CT, Stodell MA, et al. Double-blind trial of flurbiprofen and phenylbutazone in acute gouty arthritis. Br J Clin Pharmacol. 1985;20:511-3. [PMID: 3907678]

33. Lomen PL, Turner LF, Lamborn KR, Winblad MA, Sack RL, Brinn EL. Flurbiprofen in the treatment of acute gout. A comparison with indomethacin. Am J Med. 1986;80:134-9. [PMID: 3963020]

34. Siegmeth W, Placheta P. [Double-blind trial: ketoprofen versus phenylbutazone in acute gouty arthritis (author's transl)]. Wien Klin Wochenschr. 1976;88:535-7. [PMID: 793186]

35. Liu Y, Li ZC, Chen JB, Yu TT, Cui C, Zhang HB. Therapeutic efficacy of small doses of colchicine combined with glucocorticoid for acute gouty arthritis. Medical Journal of Chinese People's Liberation Army. 2015; 40:652-5

36. Rainer TH, Cheng $\mathrm{CH}$, Janssens HJ, Man CY, Tam LS, Choi YF, et al. Oral prednisolone in the treatment of acute gout: a pragmatic, multicenter, double-blind, randomized trial. Ann Intern Med. 2016; 164:464-71. [PMID: 26903390] doi:10.7326/M14-2070

37. Zhang S, Zhang Y, Liu P, Zhang W, Ma JL, Wang J. Efficacy and safety of etoricoxib compared with NSAIDs in acute gout: a systematic review and a meta-analysis. Clin Rheumatol. 2016;35:151-8. [PMID: 26099603] doi:10.1007/s10067-015-2991-1 
38. de la Torre G. A comparative, double-blind, parallel study with tenoxicam vs placebo in acute in acute gouty arthritis. Invest Med Int. 1987; 14:92-7

39. Weiner GI, White SR, Weitzner RI, Rubinstein HM. Double-blind study of fenoprofen versus phenylbutazone in acute gouty arthritis. Arthritis Rheum. 1979;22:425-6. [PMID: 371630]

40. Zhang YK, Yang H, Zhang JY, Song LJ, Fan YC. Comparison of intramuscular compound betamethasone and oral diclofenac sodium in the treatment of acute attacks of gout. Int J Clin Pract. 2014; 68:633-8. [PMID: 24472084] doi:10.1111/ijcp.12359

41. Khanna PP, Gladue HS, Singh MK, FitzGerald JD, Bae S, Prakash $\mathrm{S}$, et al. Treatment of acute gout: a systematic review. Semin Arthritis Rheum. 2014;44:31-8. [PMID: 24650777] doi:10.1016/j.semarthrit .2014 .02 .003

42. Moi JH, Sriranganathan MK, Edwards CJ, Buchbinder R. Lifestyle interventions for acute gout. Cochrane Database Syst Rev. 2013: CD010519. [PMID: 24186771] doi:10.1002/14651858.CD010519 .pub2

43. Richette $P$, Bardin T. Colchicine for the treatment of gout. Expert Opin Pharmacother. 2010;11:2933-8. [PMID: 21050036] doi:10 $.1517 / 14656566.2010 .529432$

44. Terkeltaub RA. Colchicine update: 2008. Semin Arthritis Rheum. 2009;38:411-9. [PMID: 18973929] doi:10.1016/j.semarthrit.2008.08 .006

45. van Echteld I, Wechalekar MD, Schlesinger N, Buchbinder R, Aletaha D. Colchicine for acute gout. Cochrane Database Syst Rev. 2014:CD006190. [PMID: 25123076] doi:10.1002/14651858 .CD006190.pub2

46. Wechalekar MD, Vinik O, Moi JH, Sivera F, van Echteld IA, van Durme $C$, et al. The efficacy and safety of treatments for acute gout: results from a series of systematic literature reviews including Cochrane reviews on intraarticular glucocorticoids, colchicine, nonsteroidal antiinflammatory drugs, and interleukin-1 inhibitors. J Rheumatol Suppl. 2014;92:15-25. [PMID: 25180124] doi:10.3899 /jrheum.140458

47. Borstad GC, Bryant LR, Abel MP, Scroggie DA, Harris MD, Alloway JA. Colchicine for prophylaxis of acute flares when initiating allopurinol for chronic gouty arthritis. J Rheumatol. 2004;31:2429-32. [PMID: 15570646]

48. Paulus HE, Schlosstein LH, Godfrey RG, Klinenberg JR, Bluestone R. Prophylactic colchicine therapy of intercritical gout. A placebo-controlled study of probenecid-treated patients. Arthritis Rheum. 1974;17:609-14. [PMID: 4606955]

49. Schlesinger N, Detry MA, Holland BK, Baker DG, Beutler AM, Rull $M$, et al. Local ice therapy during bouts of acute gouty arthritis. J Rheumatol. 2002;29:331-4. [PMID: 11838852]

50. Schumacher HR Jr, Becker MA, Lloyd E, MacDonald PA, Lademacher C. Febuxostat in the treatment of gout: 5-yr findings of the FOCUS efficacy and safety study. Rheumatology (Oxford). 2009;48: 188-94. [PMID: 19141576] doi:10.1093/rheumatology/ken457

51. Andrés M, Sivera F, Falzon L, Buchbinder R, Carmona L. Dietary supplements for chronic gout. Cochrane Database Syst Rev. 2014: CD010156. [PMID: 25287939] doi:10.1002/14651858.CD010156 .pub2

52. Juraschek SP, Miller ER 3rd, Gelber AC. Effect of oral vitamin C supplementation on serum uric acid: a meta-analysis of randomized controlled trials. Arthritis Care Res (Hoboken). 2011;63:1295-306. [PMID: 21671418] doi:10.1002/acr.20519

53. Wang DD, Sievenpiper JL, de Souza RJ, Chiavaroli L, Ha V, Cozma Al, et al. The effects of fructose intake on serum uric acid vary among controlled dietary trials. J Nutr. 2012;142:916-23. [PMID: 22457397] doi:10.3945/jn.111.151951

54. Holland R, McGill NW. Comprehensive dietary education in treated gout patients does not further improve serum urate. Intern Med J. 2015;45:189-94. [PMID: 25495503] doi:10.1111/imj.12661

55. Zeng YC, Huang SF, Mu GP, Wang TF. Effects of adjusted proportional macronutrient intake on serum uric acid, blood lipids, renal function, and outcome of patients with gout and overweight. Chinese Journal of Clinical Nutrition. 2012;20:210-4.
56. Choi TY, Kim TH, Kang JW, Lee MS, Ernst E. Moxibustion for rheumatic conditions: a systematic review and meta-analysis. Clin Rheumatol. 2011;30:937-45. [PMID: 21331532] doi:10.1007 /s10067-011-1706-5

57. Lee WB, Woo SH, Min BI, Cho SH. Acupuncture for gouty arthritis: a concise report of a systematic and meta-analysis approach Rheumatology (Oxford). 2013;52:1225-32. [PMID: 23424263] doi:10 .1093/rheumatology/ket013

58. Li XX, Han M, Wang YY, Liu JP. Chinese herbal medicine for gout: a systematic review of randomized clinical trials. Clin Rheumatol. 2013;32:943-59. [PMID: 23666318] doi:10.1007/s10067-013 $-2274-7$

59. Zhou L, Liu L, Liu X, Chen P, Liu L, Zhang Y, et al. Systematic review and meta-analysis of the clinical efficacy and adverse effects of Chinese herbal decoction for the treatment of gout. PLoS One. 2014;9:e85008. [PMID: 24465466] doi:10.1371/journal.pone .0085008

60. Schumacher HR Jr, Becker MA, Wortmann RL, Macdonald PA Hunt B, Streit J, et al. Effects of febuxostat versus allopurinol and placebo in reducing serum urate in subjects with hyperuricemia and gout: a 28-week, phase III, randomized, double-blind, parallel-group trial. Arthritis Rheum. 2008;59:1540-8. [PMID: 18975369] doi:10 .1002/art.24209

61. Becker MA, Schumacher HR Jr, Wortmann RL, MacDonald PA Eustace D, Palo WA, et al. Febuxostat compared with allopurinol in patients with hyperuricemia and gout. N Engl J Med. 2005;353: 2450-61. [PMID: 16339094]

62. Becker MA, Schumacher HR, Espinoza LR, Wells AF, MacDonald $P$, Lloyd $E$, et al. The urate-lowering efficacy and safety of febuxostat in the treatment of the hyperuricemia of gout: the CONFIRMS trial. Arthritis Res Ther. 2010;12:R63. [PMID: 20370912] doi:10 .1186/ar2978

63. Becker MA, Schumacher HR, MacDonald PA, Lloyd E, Lademacher C. Clinical efficacy and safety of successful longterm urate lowering with febuxostat or allopurinol in subjects with gout. J Rheumatol. 2009;36:1273-82. [PMID: 19286847] doi:10.3899/jrheum .080814

64. Becker MA, MacDonald PA, Hunt BJ, Lademacher C, JosephRidge N. Determinants of the clinical outcomes of gout during the first year of urate-lowering therapy. Nucleosides Nucleotides Nucleic Acids. 2008;27:585-91. [PMID: 18600509] doi:10 .1080/15257770802136032

65. Wu EQ, Patel PA, Mody RR, Yu AP, Cahill KE, Tang J, et al. Frequency, risk, and cost of gout-related episodes among the elderly: does serum uric acid level matter? J Rheumatol. 2009;36: 1032-40. [PMID: 19369467] doi:10.3899/jrheum.080487

66. Khanna PP, Baumgartner S, Khanna D, Storgard C, Morlock R. Assessing SUA, flare rates, and tophi in patients with gout treated xanthine oxidase inhibitors in the United States. Ann Rheum Dis. 2013;72:2013-06.

67. Hamburger MI, Tesser JRP, Skosey JL, Morton AH, Kilgore KM. Patterns of gout treatment and related outcomes in US community rheumatology practices: the relation between gout flares, time in treatment, serum uric acid level, and urate lowering therapy. Arthritis Rheum. 2012;64(Suppl 10):S808-9.

68. Yang CY, Chen CH, Deng ST, Huang CS, Lin YJ, Chen YJ, et al. Allopurinol use and risk of fatal hypersensitivity reactions: a nationwide population-based study in Taiwan. JAMA Intern Med. 2015; 175:1550-7. [PMID: 26193384] doi:10.1001/jamainternmed.2015 .3536

69. Tassaneeyakul W, Jantararoungtong T, Chen P, Lin PY, Tiamkao S, Khunarkornsiri U, et al. Strong association between HLA-B*5801 and allopurinol-induced Stevens-Johnson syndrome and toxic epidermal necrolysis in a Thai population. Pharmacogenet Genomics. 2009;19:704-9. [PMID: 19696695] doi:10.1097/FPC $.0 \mathrm{~b} 013 \mathrm{e} 328330 \mathrm{a} 3 \mathrm{~b} 8$

70. Ramasamy SN, Korb-Wells CS, Kannangara DR, Smith MW, Wang N, Roberts DM, et al. Allopurinol hypersensitivity: a systematic review of all published cases, 1950-2012. Drug Saf. 2013;36:953-80. [PMID: 23873481] doi:10.1007/s40264-013-0084-0 
71. Lee MH, Stocker SL, Anderson J, Phillips EJ, Nolan D, Williams $\mathrm{KM}$, et al. Initiating allopurinol therapy: do we need to know the patient's human leucocyte antigen status? Intern Med J. 2012;42: 411-6. [PMID: 21790926] doi:10.1111/j.1445-5994.2011.02567.x

72. Chung WH, Chang WC, Stocker SL, Juo CG, Graham GG, Lee $\mathrm{MH}$, et al. Insights into the poor prognosis of allopurinol-induced severe cutaneous adverse reactions: the impact of renal insufficiency, high plasma levels of oxypurinol and granulysin. Ann Rheum Dis. 2015;74:2157-64. [PMID: 25115449] doi:10.1136/annrheumdis -2014-205577

73. Yu KH, Lai JH, Hsu PN, Chen DY, Chen CJ, Lin HY. Safety and efficacy of oral febuxostat for treatment of HLA-B $\star 5801$-negative gout: a randomized, open-label, multicentre, allopurinol-controlled study. Scand J Rheumatol. 2016;45:304-11. [PMID: 26771445] doi: 10.3109/03009742.2015.1099729

74. Cheng L, Xiong Y, Qin CZ, Zhang W, Chen XP, Li J, et al. HLA$B \star 58: 01$ is strongly associated with allopurinol-induced severe cutaneous adverse reactions in Han Chinese patients: a multicentre retrospective case-control clinical study [Letter]. Br J Dermatol. 2015; 173:555-8. [PMID: 26104483] doi:10.1111/bjd.13688

75. Ko TM, Tsai CY, Chen SY, Chen KS, Yu KH, Chu CS, et al; Taiwan Allopurinol-SCAR Consortium. Use of HLA-B ${ }^{\star 58: 01}$ genotyping to prevent allopurinol induced severe cutaneous adverse reactions in Taiwan: national prospective cohort study. BMJ. 2015;351:h4848. [PMID: 26399967] doi:10.1136/bmj.h4848

76. Faruque LI, Ehteshami-Afshar A, Wiebe N, Tjosvold L, Homik J, Tonelli M. A systematic review and meta-analysis on the safety and efficacy of febuxostat versus allopurinol in chronic gout. Semin Arthritis Rheum. 2013;43:367-75. [PMID: 24326033] doi:10.1016/j .semarthrit.2013.05.004

77. Seth R, Kydd AS, Buchbinder R, Bombardier C, Edwards CJ. Allopurinol for chronic gout. Cochrane Database Syst Rev. 2014: CD006077. [PMID: 25314636] doi:10.1002/14651858.CD006077 .pub3

78. Tayar JH, Lopez-Olivo MA, Suarez-Almazor ME. Febuxostat for treating chronic gout. Cochrane Database Syst Rev. 2012;11: CD008653. [PMID: 23152264] doi:10.1002/14651858.CD008653 .pub2

79. Ye P, Yang S, Zhang W, Lv Q, Cheng Q, Mei M, et al. Efficacy and tolerability of febuxostat in hyperuricemic patients with or without gout: a systematic review and meta-analysis. Clin Ther. 2013;35: 180-9. [PMID: 23332451] doi:10.1016/j.clinthera.2012.12.011 80. Wechalekar MD, Vinik O, Schlesinger N, Buchbinder R. Intraarticular glucocorticoids for acute gout. Cochrane Database Syst Rev. 2013:CD009920. [PMID: 23633379] doi:10.1002/14651858 .CD009920.pub2
81. Becker MA, MacDonald PA, Hunt BJ, Jackson RL. Diabetes and gout: efficacy and safety of febuxostat and allopurinol. Diabetes Obes Metab. 2013;15:1049-55. [PMID: 23683134] doi:10.1111/dom .12135

82. Becker MA, MacDonald PA, Hunt B, Gunawardhana L. Treating hyperuricemia of gout: safety and efficacy of febuxostat and allopurinol in older versus younger subjects. Nucleosides Nucleotides Nucleic Acids. 2011;30:1011-7. [PMID: 22132950] doi:10.1080 $/ 15257770.2011 .603715$

83. Wells AF, MacDonald PA, Chefo S, Jackson RL. African American patients with gout: efficacy and safety of febuxostat vs allopurinol. BMC Musculoskelet Disord. 2012;13:15. [PMID: 22316106] doi:10 1186/1471-2474-13-15

84. Bongartz T, Zleik N, Clement M, Khun H, Crowson C, Matteson E. The risk of future attacks in patients with incident gout: a populationbased. Ann Rheum Dis. 2013;72:2013-06.

85. Halpern R, Fuldeore MJ, Mody RR, Patel PA, Mikuls TR. The effect of serum urate on gout flares and their associated costs: an administrative claims analysis. J Clin Rheumatol. 2009;15:3-7. [PMID: 19125135] doi:10.1097/RHU.0b013e3181945d2c

86. Khanna D, Hagerty D, Mischler R, Morlock R. Assessing patients that continue to flare despite apparent optimal urate lowering therapy. Ann Rheum Dis. 2013;71:2012-06.

87. Krishnan E, Akhras KS, Sharma H, Marynchenko M, Wu E, Tawk $\mathrm{RH}$, et al. Serum urate and incidence of kidney disease among veterans with gout. J Rheumatol. 2013;40:1166-72. [PMID: 23678154] doi:10.3899/jrheum.121061

88. Sarawate CA, Patel PA, Schumacher HR, Yang W, Brewer KK, Bakst AW. Serum urate levels and gout flares: analysis from managed care data. J Clin Rheumatol. 2006;12:61-5. [PMID: 16601538]

89. Andrés M, Sivera F, Falzon L, van der Heijde DM, Carmona L. Treatment target and followup measures for patients with gout: a systematic literature review. J Rheumatol Suppl. 2014;92:55-62. [PMID: 25180129] doi:10.3899/jrheum.140463

90. Loebl WY, Scott JT. Withdrawal of allopurinol in patients with gout. Ann Rheum Dis. 1974;33:304-7. [PMID: 4416909]

91. Perez-Ruiz F, Herrero-Beites AM, Carmona L. A two-stage approach to the treatment of hyperuricemia in gout: the "dirty dish" hypothesis. Arthritis Rheum. 2011;63:4002-6. [PMID: 21898351] doi: 10.1002/art.30649

92. Perez-Ruiz F, Atxotegi J, Hernando I, Calabozo M, Nolla JM. Using serum urate levels to determine the period free of gouty symptoms after withdrawal of long-term urate-lowering therapy: a prospective study. Arthritis Rheum. 2006;55:786-90. [PMID: 17013833] 
Current Author Addresses: Dr. Qaseem: American College of Physicians, 190 N. Independence Mall West, Philadelphia, PA 19106.

Dr. Harris: University of North Carolina School of Medicine, 725 Martin Luther King Boulevard, Chapel Hill, NC 27599-7590.

Dr. Forciea: University of Pennsylvania Health System, 3615 Chestnut Street, Philadelphia, PA 19104.

Author Contributions: Conception and design: A. Qaseem, R.P. Harris, M.A. Forciea, T.D. Denberg, M.J. Barry.

Analysis and interpretation of the data: A. Qaseem, R.P. Harris, M.A. Forciea, M.J. Barry, C. Boyd, N. Fitterman, L.L. Humphrey, D. Kansagara, S. Vijan, T. Wilt.

Drafting of the article: A. Qaseem, R.P. Harris, M.A. Forciea, T.D. Denberg.

Critical revision of the article for important intellectual content: R.P. Harris, T.D. Denberg, M.J. Barry, C. Boyd, R.D. Chow, N. Fitterman, L.L. Humphrey, D. Kansagara, S. Vijan, T. Wilt.

Final approval of the article: A. Qaseem, R.P. Harris, M.A. Forciea, T.D. Denberg, M.J. Barry, C. Boyd, R.D. Chow, N. Fitterman, L.L. Humphrey, D. Kansagara, S. Vijan, T. Wilt.

Statistical expertise: A. Qaseem.

Administrative, technical, or logistic support: A. Qaseem.

Collection and assembly of data: A. Qaseem, R.P. Harris.

\section{Appendix: Detailed Methods}

The evidence review was conducted by the Southern California Evidence-based Practice Center-RAND Corporation.

\section{Key Questions Addressed}

\section{Key Question 1: Acute Gout Treatment}

a. In patients with acute gout, what are the benefits and harms of different pharmacologic therapies?

b. Does effectiveness (benefits and harms) differ according to patient baseline demographic characteristics and comorbid conditions (including renal function)?

c. Does effectiveness (benefits and harms) differ according to disease severity, including initial clinical presentation (e.g., extent of joint involvement and time since start of flare) and laboratory values (serum urate [UA] levels)?

\section{Key Question 2: Dietary and Lifestyle Management of Gout}

a. In adults with gout, what are the benefits and harms of different dietary therapies and lifestyle measures on intermediate (serum UA levels) and final health outcomes (including recurrence of gout episodes and progression [e.g., development of tophi])?

b. Does effectiveness and comparative effectiveness of dietary modification differ according to disease severity (including presence of tophi and baseline serum UA level), underlying mechanisms of hyperuricemia, or baseline demographic and comorbid characteristics?

\section{Key Question 3: Pharmacologic Management of Hyperuricemia in Patients With Gout}

a. In adults with gout, what are the benefits and harms of different pharmacologic therapies on intermediate (serum UA levels) and long-term clinical health outcomes (including recurrence of gout episodes and progression)?

b. Does effectiveness and comparative effectiveness of urate-lowering therapy differ according to disease severity (including presence of tophi and baseline serum UA), underlying mechanisms of hyperuricemia, or baseline demographic and comorbid characteristics?

c. What is the effect of dietary modification in combination with pharmacologic therapy?

\section{Key Question 4: Treatment Monitoring of Patients With Gout}

a. In adults with gout, does monitoring serum urate levels with pharmacologic treatment and/or dietary and/or lifestyle change measures (e.g., adherence) improve treatment outcomes?

b. Is achieving lower subsequent serum urate levels ( $<297$ vs. 297 to $416 \mu \mathrm{mol} / \mathrm{L}[<5$ vs. 5 to $7 \mathrm{mg} / \mathrm{dL}]$ ) associated with decreased risk for recurrent acute gout attack, progression to chronic arthritis or disability, resolution of tophi, or other clinical outcomes (including risk for comorbidities or progression of comorbidities) or patient-reported outcomes?

\section{Key Question 5: Discontinuation of Pharmaceutical Management for Patients Receiving Acute or Chronic Gout Medications}

a. In adults with gout, are there criteria that can identify patients who are candidates for discontinuing:

i. Urate-lowering therapy?

ii. Anti-inflammatory prophylaxis against acute gout attack, for patients receiving urate-lowering therapy after an acute gout attack?

\section{Search Strategy}

The systematic literature search included studies published between 1 January 2010 and 1 March 2016, identified using PubMed, EMBASE, the Cochrane Library, and the Web of Science (also for unpublished or non-peer-reviewed studies), as well as ClinicalTrials .gov (from inception until 1 March 2016). Manufacturers of prescription medications used to treat gout were contacted in July 2014 for recently completed studies and unpublished or non-peer-reviewed study findings. Studies were not limited to those published in English.

\section{Quality Assessment}

The Cochrane risk-of-bias tool was used to assess the quality of individual studies for risk of bias, and AMSTAR (A Measurement Tool to Assess Systematic Reviews) was used to assess the quality of existing systematic reviews $(93,94)$. This guideline rates the evi- 
dence and recommendations by using the ACP's guideline grading system (Table 2 ).

\section{Population Studied}

The population included all adults aged 18 years or older with a diagnosis of gout.

\section{Interventions Evaluated \\ Nonpharmacologic}

Nonpharmacologic interventions included dietary interventions (low-purine diet, fructose restriction, other carbohydrate restriction, ethanol restriction, sour cherry juice, dairy products and vegetables, Mediterranean diet, and DASH [Dietary Approaches to Stop Hypertension] diet), other lifestyle measures (smoking cessation, exercise, and hydration), and dietary supplements and alternative treatments (vitamin C supplementation and traditional Chinese medicine).

\section{Pharmacologic}

Pharmacologic interventions included antiinflammatory drugs (NSAIDs and corticosteroids), colchicine, urate-lowering therapies (xanthine oxidase inhibitors and uricosuric agents), and combination drug therapies.

\section{Co-interventions}

Co-interventions included combination drug and dietary or alternative treatments.

\section{Comparators}

Comparators included placebo or usual care, other interventions, usual diet or level of activity, and early initiation of treatment.

\section{Outcomes}

\section{Diet and Lifestyle Therapy}

Outcomes included intermediate outcomes of serum urate tests; health outcomes, such as recurrence; and harms.

\section{Acute Gout}

Outcomes included efficacy, including short-term health outcomes of pain and joint swelling and tenderness; long-term outcomes, including serum urate level, pain, joint swelling and tenderness, activities of daily living, patient global assessment, and recurrence; and safety, including gastrointestinal and renal adverse effects, steroid-induced osteoporosis, and diabetes.

\section{Chronic Gout}

Outcomes included intermediate outcomes (serum urate level), final health outcomes (pain, joint swelling, tenderness associated with the development of tophi, activities of daily living, patient global assessment, risk for comorbidities or death, and recurrence of gout attacks), and safety (inflammatory, hematologic, cardiovascular, liver dysfunction, and renal dysfunction).

\section{Timing}

Studies of short-term treatment (24 to 72 hours' follow-up), long-term treatment (any follow-up time), and delayed versus immediate treatment were included.

\section{Setting}

Studies in primary care settings, including urgent care clinics and emergency departments, were included. If evidence from primary care was limited, studies of patients in specialty clinics and emergency departments were included.

\section{Target Audience}

The target audience for this guideline includes all clinicians.

\section{Target Patient Population}

The target patient population includes adults diagnosed with acute or chronic gout.

\section{Peer Review}

The AHRQ evidence review was guided by a technical expert panel that included rheumatology and general medicine specialists and methodologists. These same consultants also examined and commented on the draft final review. The draft final review was posted on the AHRQ Web site for public comments. The guideline went through a peer review process through the journal and was posted online for comments from ACP Governors and Regents. All comments were read and carefully considered by the authors, and important issues were also discussed by the CGC.

Details of the ACP guideline development process can be found in ACP's methods paper (10).

\section{Web-Only References}

93. Higgins JP, Altman DG, Gøtzsche PC, Jüni $P$, Moher D, Oxman $A D$, et al; Cochrane Bias Methods Group. The Cochrane Collaboration's tool for assessing risk of bias in randomised trials. BMJ. 2011; 343:d5928. [PMID: 22008217] doi:10.1136/bmj.d5928

94. Shea BJ, Grimshaw JM, Wells GA, Boers M, Andersson N, Hamel $C$, et al. Development of AMSTAR: a measurement tool to assess the methodological quality of systematic reviews. BMC Med Res Methodol. 2007;7:10. [PMID: 17302989] 